\title{
Manganese Substitution Effect on the Perovskite-type $\mathrm{Pb}\left(\mathrm{Zr}_{0.53} \mathrm{Ti}_{0.47}\right) \mathrm{O}_{3}$ Structure
}

\author{
S. Ibrahim, F. F. Hanna and L. K. Marei \\ Faculty of Petroleum and Mining Engineering, Suez Canal University, \\ Suez, EGYPT
}

Bulk materials of $\mathrm{Mn}$ doped $\mathrm{Pb}\left(\mathrm{Zr}_{0.53}{ }^{\mathrm{Ti}}{ }_{0.47}\right) \mathrm{O}_{3}$ of composition close to the morphotropic phase boundary have been prepared by solid state route. The influence of various $\mathrm{Mn}$ contents, 0.004, 0.008 and 0.016, on the perovskite type structure of the materials are examined using XRD technique. The types of Mn-ions substitution in the original structure are considered with respect to deviation from the ideal tolerance value $(t=1)$. The results confirmed the presence of two coexisting perovskite unit cells, tetragonal and rhombohedral, throughout the various compositions used and the rhombohedral phase becomes dominant at higher Mn contents. An attempt is also made using Rietveld to establish the exact location of the various ions displacements in the tetragonal unit cells.

\section{Introduction:}

Polycrystalline solid solutions of $\mathrm{Pb}(\mathrm{Zr} \mathrm{Ti}) \mathrm{O}_{3}$, (PZT), have been widely exploited in ceramic materials and devices because of their ferroelectric and piezoelectric properties[1,2]. A special attention is given to a compound with the formula $\mathrm{Pb}\left(\mathrm{Zr}_{0.53} \mathrm{Ti}_{0.47}\right) \mathrm{O}_{3}$, which has an excellent piezoelectric properties. In an engineering application of PZT, various doping addition have been used in order to improve the piezoelectric properties $[2,3]$.

At room temperature and ambient pressure several authors [3,4] observed the coexistence of tetragonal and rhombohedral perovskite ferroelectric phases, near the morphotropic phase boundary (MPB). The interval of the composition parameter $\mathrm{x}$ has been reported to be relatively wide and can reach $15 \mathrm{~mol} \%$ [5]. The MPB, which separates the tetragonal and rhombohedral phases, is a first order phase change, so that in the coexistence region of the two phases a complete poling for the 14 domain, 6-tetragonal and 
8-rhombohedral, orientation state is possible. In randomly axed polycrystalline ceramic PZT, ferroelectric domain walls motion is essential to allow the induction of strong polarization necessary for piezoelectricity.

Lead zirconate titanate solid solutions modification are cotrolled by aleavalent cation additions. The excess charge cation addition is called donor doped soft PZTs, and the charge deficient cation is acceptor doped hard PZTs. However, addition such as manganese, does not belong to either group.

Several researchers examined the effect of small amounts of dopants such as $\mathrm{Fe}_{2} \mathrm{O}_{3}, \mathrm{MnO}_{2}$ and $\mathrm{NiO}$ on dielectric and piezoelectric properties of perovskite material [6, 7]. It is reported [8], that the effect of $\mathrm{MnO}_{2}$ addition on PZT increases the mechanical quality factor under strong field and lowfrequency. Increasing $\mathrm{MnO}_{2}$ addition is also indicated to decrease the tetragonality of PZT [9], such a decrease is also closely related to Curie temperature.

In the present study, the effect of various amount of Mn-doped PZT on the crystal structure has been examined and its effect on both atoms displacements and also to estimate the mechanism of their relative bonding distances.

\section{Experimental:}

The system under investigation were synthesized via the conventional solid state reaction route. The raw materials were commercially available powders in oxide form of high purity: $\mathrm{PbO}\left(99 \%\right.$, Riedel Dehaen $\mathrm{Co}$.), $\mathrm{TiO}_{2}$ (99.4\%, Degussa Co.), $\mathrm{ZrO}_{2}$ (99.7\%, Strem Chemical Co.) and $\mathrm{MnO}$ (analytically pure, Strem Chemical Co.) were homogenized by an agate using $\mathrm{ZrO}_{2}$ ball and isopropyl alcohol as milling media. Following drying at $150^{\circ} \mathrm{C}$ for $2 \mathrm{hrs}$, calcination was carried at $850^{\circ} \mathrm{C}$ for $2 \mathrm{hrs}$ in air and subsequently ball-milled for $3 \mathrm{hrs}$ to break up the agglomerates. The calcined powders were consolidated into green compacts of $10 \mathrm{~mm}$ diameter and 2-3 $\mathrm{mm}$ thickness under a normal load $690 \mathrm{MPa}$ using water as a binder. The compact powders were dried at $150^{\circ} \mathrm{C}$ for $2 \mathrm{hrs}$ to burn out the binder. The prepared green compacts were placed in a closed alumina crucible embedded in a mixture of $\left[\mathrm{PbZrO}_{3}+10 \% \mathrm{ZrO}_{2}\right]$ to ensure a constant lead oxide activity. A platinum foil isolation was also used to ensure that no solid state diffusion or liquid phase transfer occurred between atmosphere powder and samples.

Moreover, in order to avoid lead deficient during sintering, $\mathrm{PbO}$ excess $3 \mathrm{~mol} \%$ was added to stoichiometric composition. Excess lead addition is also 
expected to ensure higher densification of the ceramic material via liquid phase sintering mechanism. Sintering was carried aut at $1100^{\circ} \mathrm{C}$ for $2 \mathrm{hrs}$ in air and finally cool to room temperature.

Four PZTs compositions were used in the present investigation, the first with the stoichiometric composition $\mathrm{Pb}\left(\mathrm{Zr}_{0.53} \mathrm{Ti}_{0.47}\right) \mathrm{O}_{2}$ the three other composition were doped with $\mathrm{MnO}_{2}$ to give $\mathrm{Pb}\left(\mathrm{Zr}_{0.53} \mathrm{Ti}_{0.47-\mathrm{X}} \mathrm{Mn}_{\mathrm{X}}\right) \mathrm{O}_{3}$ with $\mathrm{x}=$ $0.004,0.008$ and 0.016 at the expense of $\mathrm{Ti}-$ content.

The samples were examined by XRD using a Siemens D500 X-ray diffractometer. The voltage and currents ratings used were $40 \mathrm{kV}, 30 \mathrm{~mA}$, with $\mathrm{CuK}_{\alpha}$ radiation, $(\lambda=1.54056 \AA)$. The $2 \theta$ range was $10^{\circ}-80^{\circ}$ in a step scan mode with step angle of 0.04 degree and $3.0 \mathrm{~s}$ allowed time for detection. The diffraction patterns have been analyzed by Rietveld method using the FULLPROF program (version 3.5d Oct 98-LLB-JRC).

\section{Results and discussion:}

3.1Calculation of tolerance factor and unit cell parameters.

The distortions of the perovskite $\left(\mathrm{ABO}_{3}\right)$ structure with respect to the ideally cubic stable one are controlled by the tolerance factor:

$$
t=\frac{\left(r_{A}+r_{O}\right)}{\sqrt{2}\left(r_{B}+r_{O}\right)},
$$

where $r_{A}, r_{B}$ are the cation radii with 12 and 6-coordinated respectively and $r_{o}$ is the oxygen anion radius in sixfold coordination [10]. For ideal cubic perovskite structure $\mathrm{t}=1$ and the apparent contraction of the octahedral sublattice with respect to ideal structure is quantified by $\Delta \mathrm{a}=\left(\mathrm{a}_{\text {cal. }}-\mathrm{a}_{\text {mpeas. }}\right)$. Assuming that all the ions are hard spheres, the lattice parameter a of the cubic perovskite is given as:

$$
\begin{aligned}
a & =2\left(r_{B}+r_{O}\right) \\
\text { or } \quad a & =\frac{2\left(r_{A}+r_{O}\right)}{\sqrt{2}}
\end{aligned}
$$

In relation (1), the lattice parameter is determined by the length of the bond $\mathrm{B}-\mathrm{O}$, since the $\mathrm{B}-\mathrm{O}-\mathrm{B}$ ion arrangement is more compact than A-O-A arrangement in the ideal $\mathrm{ABO}_{3}$ structures, such as $\mathrm{PbTiO}_{3}$ and $\mathrm{PbZrO}_{3}$. In the present system the B-ion is occupied by three different ions, $\mathrm{Zr}$, Ti and $\mathrm{Mn}$. 
When Equation (1) is used, the obtained lattice parameters are higher compared to the actual a-values measured from the refinement XRD pattern. This deviation could have several reasons, such as deviation from the ideal cubic perovskite structure. An average multiplication factor has been introduced to Equation (1) in order to obtain a value closer to the measured one [16]. This factor is estimated from the ratio between measured values and the values from Equation (1) which become,

$$
a=2\left(r_{B}+r_{O}\right) 0.979
$$

Equation (3) is then used to calculate the theoretical unit cell parameters, for the structures with various Mn-substitution content, Table (1), assuming ideal perovskite structure which is cubic.

Table (1): Unit-cell parameter of the tetragonal phases for Mn-substitution of $\mathrm{Pb}\left(\mathrm{Zr}_{0.53}{ }^{\mathrm{Ti}_{0.47 x}} \mathrm{Mn}_{\mathrm{X}}\right) \mathrm{O}_{3}$ compared with the refinement data.

\begin{tabular}{|c|c|c|c|c|c|}
\hline $\begin{array}{l}\text { Mn-content } \\
(x)\end{array}$ & $\begin{array}{c}\left.\text { acal. }^{(\AA)}\right) \\
\text { Eq. (3) }\end{array}$ & $V_{\text {cal. }}\left(\AA^{3}\right)$ & $\underset{\text { (refin.) }}{a_{\text {measur. }}(\AA)}$ & $V_{\text {measur. }}\left(\AA^{3}\right)$ & $\mathbf{c} / \mathbf{a}$ \\
\hline 0.000 & 4.041 & 65.988 & 4.0885 & 67.306 & 1.007 \\
\hline 0.004 & 4.040 & 65.939 & 4.0675 & 66.526 & 1.008 \\
\hline 0.008 & 4.039 & 65.890 & 4.0682 & 68.681 & 1.016 \\
\hline 0.016 & 4.038 & 65.841 & 4.0665 & 66.420 & 0.977 \\
\hline
\end{tabular}

The tolerance factor can be qualitatively used as a measure of bond length mismatch in the cubic perovskite structure. On the other hand, for ionic crystal internal lattice energy is considered to be the results of both a long-range electrostatic force and a short-range force which include the repulsion force as a main part in addition to Van der Waals, vibrational and covalent contribution [11]. Many attempts to correlate tolerance factor and internal lattice energy measurement for the solid solution $\mathrm{Pb}\left(\mathrm{Zr}_{0.53} \mathrm{Ti}_{0.47}\right) \mathrm{O}_{3}$ have indicated that for ideal perovskite $t=1$, both electrostatic and non-electrostatic energy terms are equal in magnitude and negative in sign at the intermediate ratio of $\mathrm{Zr} / \mathrm{Ti}$ [12]. Therefore, a minimum ionic crystal energy is expected the closer the value of $t$ to 1 . Table (2) shows a comparison between different tolerance factor values obtained for the different compositions of PZTs materials. The variation in tvalues are extended to the different ionic state substitution for $\mathrm{Mn}^{4+}, \mathrm{Mn}^{3+}$ and $\mathrm{Mn}^{2+}$. It is generally possible to indicate for all PZTs compositions (t) is less than one and is closer to ideal value with Mn-substitution as $\mathrm{Mn}^{4+}$ followed by a lower $\mathrm{Mn}^{3+}$ and $\mathrm{Mn}^{2+}$. Therefore, 
Mn-substitution could then more energetically favorable for $\mathrm{Mn}^{4+}$ compared with $\mathrm{Mn}^{3+}$ and $\mathrm{Mn}^{2+}$.

Table (2): Tolerance factor (t) for $\mathrm{Pb}\left(\mathrm{Zr}_{0.53}{ }^{\mathrm{Ti}} 0.47-\mathrm{x} \mathrm{Mn}_{\mathrm{x}}\right) \mathrm{O}_{3}$ series.

\begin{tabular}{|c|c|c|c|}
\hline \multirow{2}{*}{$\begin{array}{c}\text { Mn-content } \\
\text { (x) }\end{array}$} & \multicolumn{3}{|c|}{ Tolerance factor (t) } \\
\cline { 2 - 4 } & \multicolumn{2}{|c|}{ B-substitution } & A-substitution \\
\hline & $\mathrm{Mn}^{4+}$ & $\mathrm{Mn}^{3+}$ & $\mathrm{Mn}^{2+}$ \\
\cline { 2 - 4 } 0.000 & 0.9904 & - & 0.9904 \\
0.004 & 0.9906 & $\overline{-}$ & 0.9887 \\
0.008 & 0.9908 & 0.9905 & 0.9894 \\
0.016 & 0.9910 & 0.9906 & 0.9883 \\
\hline
\end{tabular}

Moreover, the existence of $\mathrm{Mn}^{4+}$ and $\mathrm{Mn}^{2+}$ in ionic state for substitution in PZT material is confirmed, thought is not case for $\mathrm{Mn}^{3+}$, since it is not detected by electron spin resonance spectrum measurement [9]. However, as indicated above B-site substitution ion is expected to be more favorable by the small $\mathrm{Mn}^{4+}$ ions, the possible existence of trivalent $\mathrm{Mn}^{3+}$ on B-site cannot be excluded. For the substitution of $\mathrm{Mn}$ in $\mathrm{BaTiO}_{3}$ perovskite structure, it is suggested that the higher resistivity values observed could be due to manganese stabilization in oxidation state of $\mathrm{Mn}^{3+}$ [13].

\subsection{Structure analysis.}

The XRD patterns of the four PZTs compositions are shown in Fig. (1), they were indexed as two phases of perovskite type, tetragonal and rhombohedral. The addition of $3 \mathrm{~mol} \% \mathrm{PbO}$ to each composition in order to compensate for lead volatilization which is expected to take place during sintering at $1100^{\circ} \mathrm{C}$, is proved to be useful, since no extra lines for a second phase have been detected in various patterns. 


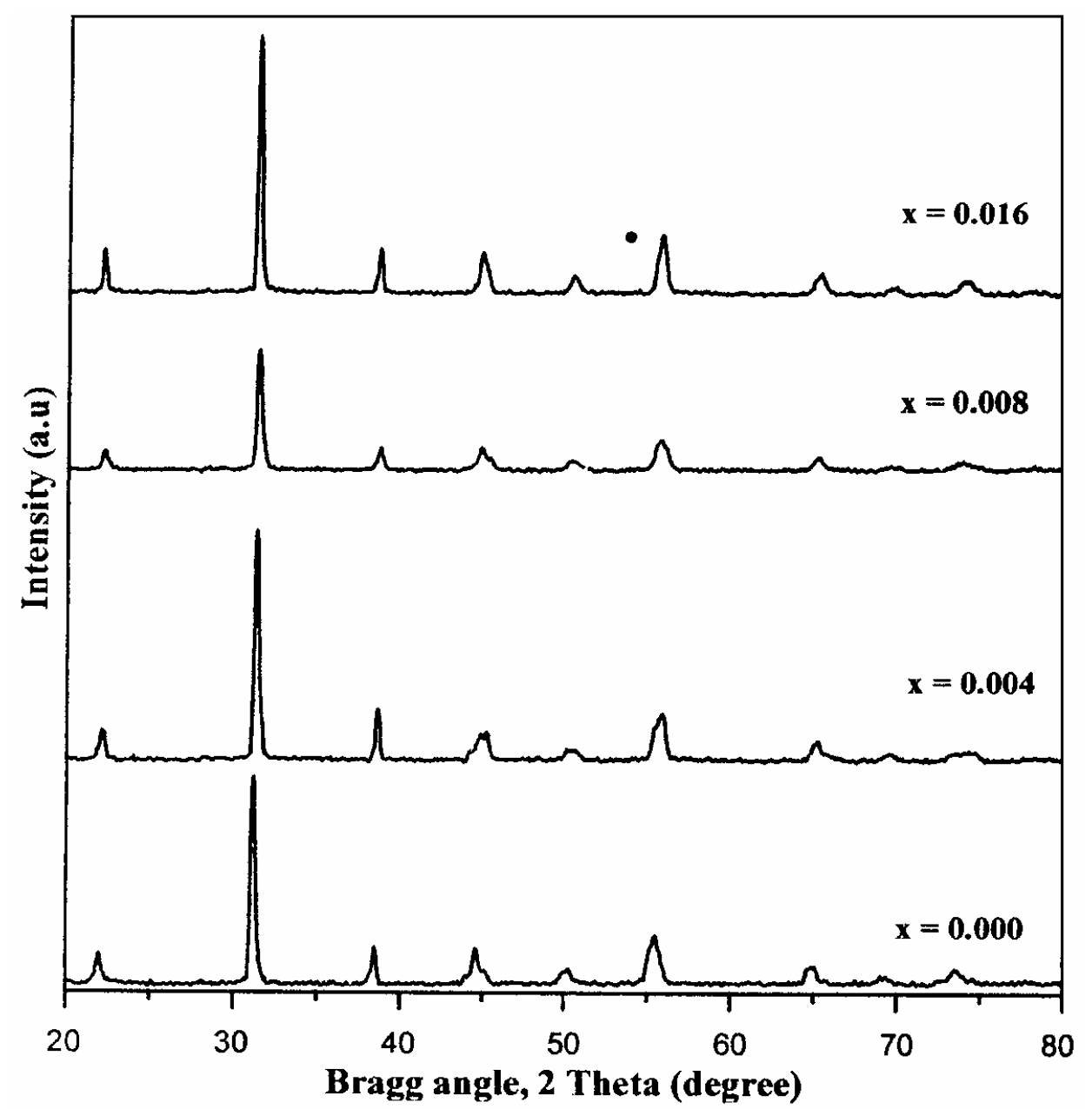

Fig. (1) : XRD patterns of $\mathrm{Pb}\left(\mathrm{Zr}_{0.53} \mathrm{Ti}_{0.47-\mathrm{X}} \mathrm{Mnx}\right)_{\mathrm{O} 3}$

Rietveld refinements have been satisfactory performed assuming that the space group is $\mathrm{P} 4 \mathrm{~mm}$ for the tetragonal phase and $\mathrm{Pm} 3$ for the rhombohedral one. In this analysis, background, peaks shape, lattice parameters and atomic positions are refined. For the polar axes, z-direction, the two oxygen ions with different positions are refined independently of the octahedral central ions which is either Ti or Zr-ion or the substituted Mn-ion. Such assumption is based on the fact that the used PZTs compositions are ferroelectric below the Curie temperature have a shift of $\mathrm{Zr}$ and/or $\mathrm{Ti}$ and $\mathrm{O}$-ions relative to A site cation [4]. 
The refinement results are shown in both Table (3) and in Fig. (2). It is to be indicated that the peaks of the two perovskite phases are highly superimposed at almost all angles in the examined ranges, therefore, the refinement calculation of the two phase weigh percentage is not quit acceptable. However, tetragonal $(\mathrm{T})$ phase has a double peaks of certain diffraction such as (100) and (200), which is not the case for rhombohedral (R), and therefore their relative intensities can be used to estimate the relative weight of each phase in the structure. The extended XRD patterns of $(200)_{\mathrm{R}}$ and $(200)_{\mathrm{T}} \&(002)_{\mathrm{T}}$ peaks for the basic compositions and various Mn-substitution compositions are superimposed and shown in Fig. (3). The double diffraction of the tetragonal phase has been observed to diminish with increasing Mn-substitutions while an almost single rhombohedral peak is obtained with 0.016 Mn PZT material. Moreover, the relative measured intensities of $(200)_{\mathrm{T}}$ and $(200)_{\mathrm{R}}$ indicated a continuous decrease of tetragonal peak with an increases of the rhombohedral peak with $\mathrm{Mn}$ - content, Table (4). This could suggest that the relative weight of the rhombohedral phase increases on the expanse of tetragonal phase with increasing Mn-substitution of basic PZT composition. A possible long-range order and disorder of $\mathrm{Zr}$ and $\mathrm{Ti}$ substitution by $\mathrm{Mn}$-ions may contribute to this simultaneous competition between tetragonal and rhombohedral near the morphotropic phase transition.

Table (3): Crystal data for tetragonal phase of $\mathrm{Pb}\left(\mathrm{Zr} 0.53^{\mathrm{Ti}} 0.47-\mathrm{x}_{\mathrm{x}} \mathrm{O}_{3}\right.$ (space group $\mathrm{p} 4 \mathrm{~mm}$ ).

\begin{tabular}{|c|c|c|c|}
\hline Mn-content (x) & $\mathbf{R}_{\mathbf{p}} \mathbf{( \% )}$ & $\mathbf{R}_{\mathbf{w p}} \mathbf{( \% )}$ & Goodness of fit \\
\hline 0.000 & 10.80 & 14.00 & 1.10 \\
0.004 & 10.20 & 13.60 & 1.05 \\
0.008 & 10.70 & 13.60 & 0.650 \\
0.016 & 08.34 & 10.70 & 0.656 \\
\hline
\end{tabular}

Table (4): Relative intensities of (200)T and (200)R peaks: IT $=\mathrm{I}(200) \mathrm{T} /$ $\mathrm{I}(101) \mathrm{T} \& \mathrm{IR}=\mathrm{I}(200) \mathrm{R} / \mathrm{I}(110) \mathrm{R}$.

\begin{tabular}{|c|c|c|}
\hline Mn-content (x) & Rel. Int. of $\mathbf{( 2 0 0}_{\mathbf{T}}$ & Rel. Int. of $\mathbf{( 2 0 0 )})_{\mathbf{R}}$ \\
\hline 0.000 & 0.373 & 0.199 \\
0.004 & 0.447 & 0.222 \\
0.008 & 0.366 & 0.234 \\
0.016 & 0.134 & 0.242 \\
\hline
\end{tabular}




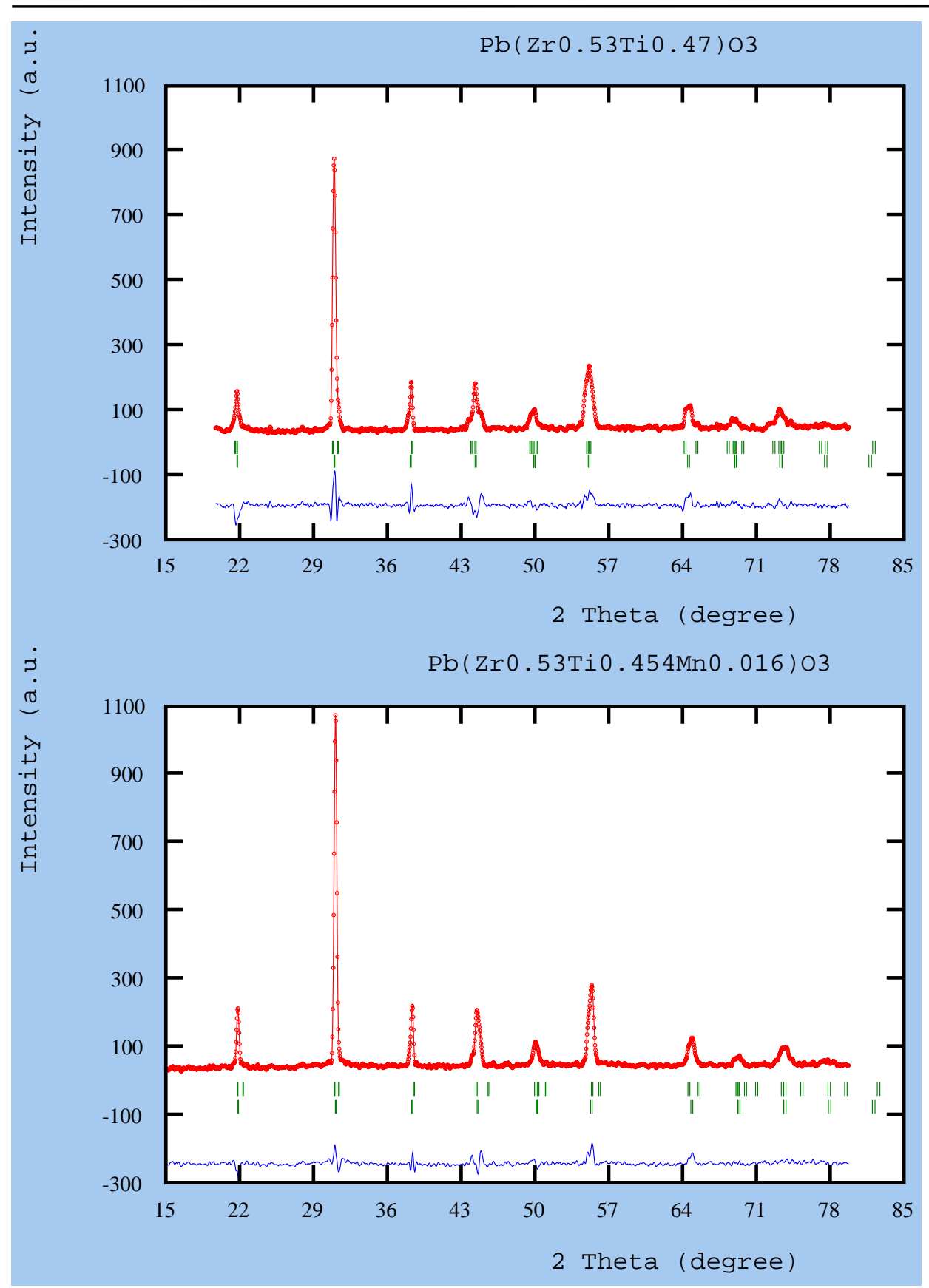

Fig. (2): Observed (circle) and calculated (cross) diffraction patterns of $\mathrm{Pb}\left(\mathrm{Zr}_{0.53} \mathrm{Ti}_{0.47-\mathrm{x}}\right.$ $\left.\mathrm{Mn}_{\mathrm{x}}\right) \mathrm{O}_{3}$ measured at room temperature [as an examples $\mathrm{x}=0.000$ and 0.016 ]. The location of expected reflections and the difference between observed and calculated patterns are shown beneath 


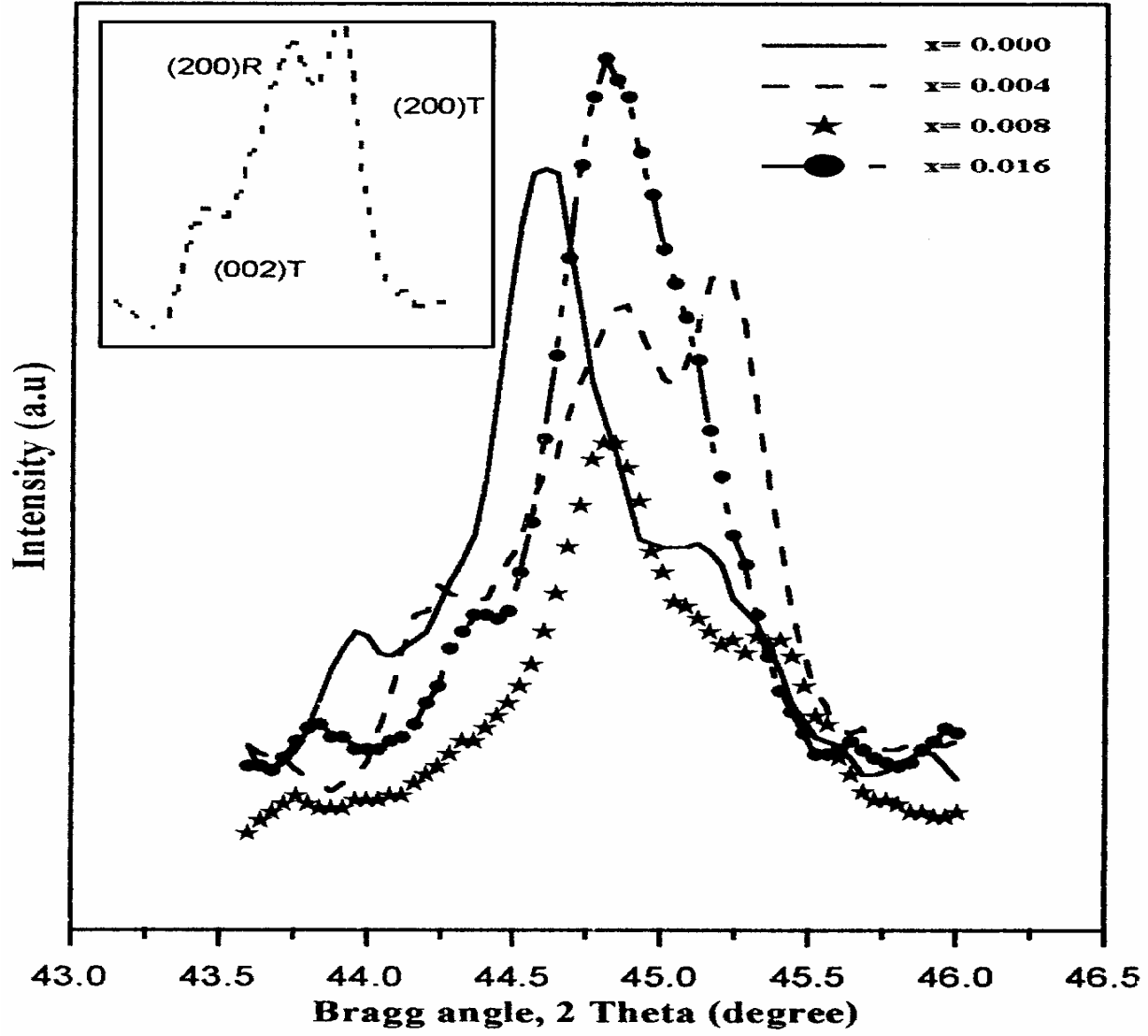

Fig. (3) : The superim posed of (200) R and (200) T \& (002) T reflections of $\mathrm{Pb}\left(\mathrm{Zr}_{0.53} \mathrm{Ti}_{0.47-\mathrm{X}} \mathrm{Mnx}\right)_{\mathrm{O} 3}$

The calculated lattice constant change with Mn-substitution are shown in Table(1), the slight difference observed can possibly be due to the increasing presences of Mn-ions in the structure. The measured lattice-constant of tetragonal phase vary with compositions and differs from the calculated values. Such difference may possible be related to the atomic displacement due to ferroelectric phenomenon in the PZTs materials. Also, it is known that in perovskite structure when a smaller ions substitute of either B or A sites, or when there is a difference in ionic charge between the original and substituted atoms, this will create a deficient in the structure. Such deficient can be compensated by vacancies formation in the structure in order to maintain the mass and charge neutrality. In addition vacancies concentration in this type of material also depend on $\mathrm{Zr} / \mathrm{Ti}$ ratio [13]. The substitution of $\mathrm{Mn}^{4+}$ ions for $\mathrm{Ti}^{4+}$ ions positions in accordance with the chemical formula $\mathrm{Pb}\left(\mathrm{Zr}_{0.53} \mathrm{Ti}_{0.47-\mathrm{x}} \mathrm{Mn}_{\mathrm{x}}\right) \mathrm{O}_{3}$, would results in lower Ti-composition. 
Measured unit-cell volumes and the (c/a) ratio for the tetragonal phases are shown in Table (1). However, inconsistent appears in the result, mainly for $0.008 \mathrm{Mn}$-composition., the unit-cell volume decreases in general with $\mathrm{Mn}$ additions. It is to be noted that with Mn substitution a turning point is present in $\left(\mathrm{c}_{\mathrm{T}} / \mathrm{a}_{\mathrm{T}}\right)$ value close to $0.008 \mathrm{Mn}$ addition has been reported [9]. A possible explanation for unit cell volume changes could be related to both Mn-ionic state which will be substituted $\left(\mathrm{Mn}^{4+}, \mathrm{Mn}^{3+}\right.$ or $\left.\mathrm{Mn}^{2+}\right)$ and its location in the unit cell. Rietveld simulation have been attempted to distinguish whether the substitution site for Mn-ions is A or B site. This attempt has failed because the intensity difference between the two formula are less than the experimental error of XRD [14]. The changes in tetragonality parameter $\left(\mathrm{c}_{\mathrm{T}} / \mathrm{a}_{\mathrm{T}}\right)$ ratio could be also related to $\mathrm{Zr} / \mathrm{Ti}$ ratio. Since, at the MPB, the two phase tetragonal and rhombohedral are in equilibrium i.e. $\mathrm{Zr} / \mathrm{Ti}$ ratio $\approx 0.53 / 0.47$, and both phases are rather close to the cubic perovskite. Therefore, changing the composition toward a relatively higher $\mathrm{Zr}$-content the structure become progressively unstable and $\mathrm{T} \rightarrow \mathrm{R}$ transition becomes more likely. The driving force for such transition could be related to requermint of the center ions coordination movement with less distortion in the lattice.

Furthermore, the results of the XRD for the various PZTs compounds conform such concepts, since a gradual increases in the rhombohedral phase as Mn increases, as shown by intensities analysis. The lattice constant of the rhombohedral changes with Mn-substitution, the unit cell volumes and the angles $\alpha$ are shown in Table (5). It is so noted that the change in angles $\alpha$ with Mn-substitution is considered to be a measure of ferroelectric distortion i.e., spontaneous strain, for the rhombohedral phase and is given by $(90-\alpha / 90)$.

Table (5): The rhombohedral lattice constants' changes with the $\mathrm{Mn}$ substitutions.

\begin{tabular}{|c|c|c|c|}
\hline Mn-content $\mathbf{( x )}$ & $\mathbf{a}(\boldsymbol{\AA})_{\text {meas. }}$ & $\mathbf{V ~ ( \AA )} \mathbf{~}_{\text {meas. }}$ & $\alpha(\mathbf{d e g})_{\text {meas. }}$ \\
\hline 0.000 & 4.084 & 68.099 & 90.157 \\
0.004 & 4.063 & 67.082 & 90.011 \\
0.008 & 4.076 & 67.706 & 90.263 \\
0.016 & 4.067 & 67.255 & 89.991 \\
\hline
\end{tabular}

The high symmetry $\mathrm{ABO}_{3}$ perovskite structure is paraelectric above the curie temperature in simple cubic with oxygen almost at face centers and $\mathrm{A}(\mathrm{Pb})$ and $\mathrm{B}(\mathrm{Zr}, \mathrm{Ti})$ at the cubic corner and body centers respectively. At low temperature and near MPB simultaneous competition between rhombohedral and tetragonal phase transition exists, those phases contribute to the ferroelectric properties of the material. The onset of polarization in perovskite ferroelectric can be described by shift of the central atoms $\mathrm{Ti}$ and $\mathrm{Zr}$ as well the 
oxygen atoms relative to the large $\mathrm{A}$-site $\mathrm{Pb}$ atoms, the larger the shift the larger is the spontaneous polarization in PZT material $[2,3]$.

For the present PZTs compositions, the $\mathrm{Zr}$ to Ti ratio could be easily approximated to $1: 1$ ions and if a periodic large unit cell is assumed for eight center atoms, four will be occupied by $\mathrm{Zr}$, two along $<110>$ direction and the other two along $<011>$ directions for optimum geometry [15]. Such distribution allows oxygen atoms to move outward displacement. The atomic coordination for $\mathrm{Zr}$, Ti and $\mathrm{Mn}$ ions values, are shown in Table (6), of two PZTs compositions for comparison and the two $\mathrm{O}_{1}$ and $\mathrm{O}_{2}$ positions, $(\mathrm{x}, \mathrm{y}, \mathrm{o})$ and $(\mathrm{x}, \mathrm{o}, \mathrm{z})$. It is obvious that Mn-substitution has an influence on the atomic coordinates, in general a lower displacements are obtained when Mn-atoms is added, Table (6). The displacement pattern also gives a different values for $\mathrm{Zr}$ and $\mathrm{Ti}$, suggesting a possible different bonding length types with oxygen. Moreover, from Table (6) it is also possible to observe that various ions coordination vary with composition or it could be rather the various states of Mn-substitution i.e. Mn-radius which affects the overall ions coordination.

Table (6): The atoms coordinates of both $\mathrm{Pb}\left(\mathrm{Zr}_{0.53} \mathrm{Ti}_{0.47}\right) \mathrm{O}_{3}$, and $\mathrm{Pb}\left(\mathrm{Zr}_{0.53} \mathrm{Ti}_{0.462} \mathrm{Mn}_{0.008}\right) \mathrm{O}_{3}$ tetragonal phases.

\begin{tabular}{|c|c|c|c|}
\hline \multirow{2}{*}{ Ion } & \multicolumn{3}{|c|}{$\mathbf{P b}\left(\mathbf{Z r}_{\mathbf{0 . 5 3}} \mathbf{T i}_{\mathbf{0 . 4 7}}\right) \mathbf{O}_{\mathbf{3}}$} \\
\cline { 2 - 4 } & $\mathbf{x}$ & $\mathbf{y}$ & $\mathbf{z}$ \\
\hline $\mathbf{Z r}^{4+}$ & 0.50 & 0.50 & 0.659 \\
$\mathbf{T i}^{4+}$ & 0.50 & 0.50 & 0.562 \\
$\mathbf{O}_{\mathbf{1}}$ & 0.50 & 0.50 & 0.076 \\
$\mathbf{O}_{\mathbf{2}}$ & 0.50 & 0.00 & 0.672 \\
\hline \multicolumn{4}{|c|}{$\mathbf{P b}\left(\mathbf{Z r}_{\mathbf{0 . 5 3}} \mathbf{T i}_{\mathbf{0 . 4 6 2}} \mathbf{M n}_{\mathbf{0 . 0 0 8}}\right) \mathbf{O}_{\mathbf{3}}$} \\
\hline $\mathbf{Z r}^{4+}$ & 0.50 & 0.50 & 0.514 \\
$\mathbf{T i}^{4+}$ & 0.50 & 0.50 & 0.542 \\
$\mathbf{O}_{\mathbf{1}}$ & 0.50 & 0.50 & 0.055 \\
$\mathbf{O}_{\mathbf{2}}$ & 0.50 & 0.00 & 0.612 \\
$\mathbf{M n}^{4+}$ & 0.50 & 0.50 & 0.459 \\
\hline
\end{tabular}

\section{Conclusion:}

$\mathrm{Mn}$ - doped $\mathrm{Pb}(\mathrm{Zr} \mathrm{Ti}) \mathrm{O}_{3}$ of composition close to the morphotropic phase boundary have been prepared by solid state route where an excess of 3 $\mathrm{mol} \% \mathrm{~Pb}$ is found to be a necessary addition for each composition in order to compensate the lead loss during material processes. The PZTs materials with Mn - substitution have shown two phases coexisting, with a domination of the rhombohedral phase at higher Mn contents. The tolerance factor calculations suggested that the most likely ionic state for Mn-substitution is rather $\mathrm{Mn}^{4+}$ ions followed by possible $\mathrm{Mn}^{3+}$ ions. Relatively small lattice constants changes are 
found to be composition dependent and have been related to $\mathrm{Zr} / \mathrm{Ti}$ ratio and Mncontent. A reasonable high degree of fitting is obtained by Rietveld analysis based on the assumption of two phases coexistence. Possible defects in the structure, however excluded in the analysis, could be responsible for the discrepancy observed. Ferroelectrical ions coordination in the tetragonal perovskite structure are estimated and found to be mainly affected by ionic radius as well as its site occupation.

\section{Acknowledgments:}

The authors are indebted to Prof. A. M. Shamah for many helpful discussions and introducing his facilities during the x-ray measurements.

\section{References:}

1. Mehmet A. Akbus, Michael A. Mecoy and William C. Lee, J. Am. Ceram. Soc. 78. 9, 2417 (1995).

2. Kelly Markowski, Seung-Lek Park, Shoko Yoshikawa, and L. Eric cross. J. Am. Ceram. Soc. 79.12, 3297 (1996).

3. Takenobu Saka and Hiroshi Kawamoto. J. Am. Ceram. Soc. 83. 6, 1423 (2000).

4. Dragon Domyenovic, Rep. Prog. Phys. 61, 1267 (1998).

5. V. A. Isupov, Fiz. Tverd. Tela. 22, 172 (1980).

6. K. H. Hardil, J. Am. Ceram. Soc. 64, 283 (1981).

7. T. B. Weston, A. H. Webster and V. M. Mc Namara: J. Am. Ceram. Soc. 52, 253 (1969).

8. P. Roy-Chowdhviy and S. B. Deshpander, J. Matter. Sci. 22, 2209 (1987).

9. T. Kamiya, T. Suzki, T. Tsurumi and M. Doimen: JPn. J. App. Phys. 31, 3058 (1992).

10. R. D. Shannon: Acta crystallogr. A 32, 751 (1976).

11. Takayawa-Muromachi E and Navrotsky A, J. Solid State Chem. 72, 244 (1983).

12. G. Ajr. Rossctti and A. Navrotsky, J. Solid State Chem. 144, 188 (1999).

13. S. R. Kokare, S. A Pawar, N. T Padal and P.B Joshi, Bull. Mater. Sci. 24, 248 (2001). Indian Academy of Science.

14. Hyn-Bum, Park, Chan Young park, Young-Sik Hang, Keom Kim and SiJoony Kim, J. Am. Ceram. Soc. 82, 94 (1999).

15. L. Bellaiche, J. Padilla and D. Vanderbilt, Cond. Mat. 19, 109 (1998).

16. Lon M. Reaney, Enrico Colla and Mova Setter, Jpn. J. Appl. Phys. 33, 3984 (1994). 